\title{
Variabilidad genética de la bacteria Ralstonia solanacearum (Burkholderiales: Burholderiaceae) en la zona bananera de Urabá (Colombia)
}

\author{
Carolina Cardozo ${ }^{1}$, Paola Rodríguez ${ }^{2}$, José Miguel Cotes ${ }^{1} \&$ Mauricio Marín $^{1}$ \\ 1. Universidad Nacional de Colombia sede Medellín, Laboratorio de Biología Celular y Molecular, Cra 64 x Calle 65, \\ Autopista Norte, Medellín, Colombia; mamarinm@unal.edu.co \\ 2. Centro de Investigaciones del Banano, Cenibanano, Augura, Calle 3 Sur No 41-65, piso 9, Medellín, Colombia; \\ paolaandrea.rodriguez@bayercropscience.com
}

Recibido 03-IV-2009. Corregido 10-X-2009. Aceptado 20-X-2009.

\begin{abstract}
Genetic variability of the bacterium Ralstonia solanacearum (Burkholderiales: Burholderiaceae) in the banana-growing region of Uraba (Colombia). The banana moko disease, caused by the bacterium Ralstonia solanacearum, is one of the most important phytopathological problems of the banana agribusiness in tropical countries. In Uraba and Magdalena (Colombia), the main exporting regions of banana in Colombia, this disease causes a destruction estimated in 16.5 ha/year. The bacterium presents an extremely high level of genetic variation that affects control measures. This is the first study of its variation in Colombia and was done with AFLP molecular markers on a population of 100 isolates from banana plants, soils and "weeds". The high level of genetic diversity, with Nei and Shannon indexes of $\mathrm{h}=0.32$ and $\mathrm{I}=0.48$, respectively, and the AMOVA, showed that this population is subestructured $(\mathrm{Fst}=0.66$ ): the host is the main factor of differentiation. Even so, previous tests show that all varieties have pathogenicity on Musa. Rev. Biol. Trop. 58 (1): 31-44. Epub 2010 March 01.
\end{abstract}

Key words: AFLP, moko disease, molecular markers, Musa sp., Ralstonia solanacearum.

La Agroindustria de producción de banano en Colombia es la tercera fuente generadora de divisas del sector agropecuario, con un valor que oscila entre 400 y 440 millones de dólares al año. Esta actividad económica se concentra en las regiones de Urabá (Antioquia) y el Nororiente del Departamento de Magdalena, en donde se cultivan cerca de 44000 ha que producen 1399623 ton de fruta fresca y genera 35000 empleos directos (Ministerio de Agricultura y Desarrollo Rural 2006).

Desde el punto de vista fitosanitario, el cultivo del banano presenta diversas limitantes biológicas, entre las que se destacan la Sigatoka negra (Mycosphaerella fijiensis) y el Moko causado por la bacteria Ralstonia solanacearum (Smith) (Yabuuchi et al. 1995). Se estima que el Moko provoca pérdidas para la región de Urabá de 16.5 ha anuales de área productiva, lo que representó la destrucción de 528 ha de cultivo en el período entre 1970 y 2000 (Castañeda \& Espinosa 2005). El efecto directo de esta enfermedad se agrava por la capacidad de su agente causal de sobrevivir por largos períodos de tiempo en el suelo, inhabilitando la resiembra inmediata de los lotes afectados. Adicionalmente, la gran plasticidad genética de la bacteria, la carencia de genotipos de banano resistentes a su ataque, el alto número de plantas arvenses hospedantes que presenta y su fácil dispersión, dificultan las prácticas dirigidas a su control (Fegan \& Prior 2006).

$R$. solanacearum es un fitopatógeno altamente agresivo con una distribución global y un inusual amplio rango de hospedantes, 
que incluye cientos de plantas de al menos 50 familias botánicas diferentes (Hayward 1995). Algunos de sus hospedantes de importancia económica son: la papa, el tomate, el tabaco, el banano, la heliconia, el anturio y el maní. Esta especie era considerada hasta hace algunos años, del grupo de Pseudomonas no fluorescentes, pero actualmente se considera un miembro del género Ralstonia ubicado en el Dominio Bacteria, División Gracillicutes, Clase Proteobacteria, Subclase $\beta$.

En diferentes estudios moleculares, bioquímicos y patogénicos se ha encontrado que $R$. solanacearum es una especie heterogénea que debe considerarse como un complejo, es decir como un grupo de aislamientos relacionados cuyos miembros individuales pueden representar más que una especie (Fegan \& Prior 2005). El término complejo de especies fue inicialmente aplicado a $R$. solanacearum por Gillings \& Fahy (1994) para reflejar el grado de variación fenotípica y genotípica encontrada dentro de esta especie. Luego, Taghavi et al. (1996) expandieron el concepto para incluir a la bacteria que causa la enfermedad BDB (Blood disease bacterium) del banano y P. syzygii, el agente causal de la enfermedad de Sumatra de plantas de clavo de olor (Syzgyum aromaticum).

Desde el punto de vista genético, la especie se ha segmentado en dos divisiones (I y II) determinadas a partir del análisis de RFLP's de una colección mundial de aislamientos (Cook et al. 1989). La División I comprende representantes de los biovares 3, 4 y 5 principalmente encontrados en Asia; mientras que la División II contiene los biovares 1, 2 y N2 de origen americano, los que se caracterizan por ser metabólicamente poco versátiles. Esta agrupación fue posteriormente confirmada mediante análisis de las secuencias $16 \mathrm{~S}$ del ADNr (Taghavi et al. 1996), estudio que además demostró la existencia de un subgrupo dentro de la División II, conformado por aislamientos de $R$. solanacearum obtenidos en Indonesia y por los organismos relacionados BDB y $P$. syzygii. Este linaje genético fue luego confirmado mediante secuenciación directa de la región intergénica del $\mathrm{ADNr}$ (ITS) y de los genes que codifican para poligalacturonasa y endoglucanasa (Fegan et al. 1998). Por otra parte, Poussier et al. (2000) demostraron la existencia de un subgrupo de aislamientos de origen africano dentro del biovar 1, mediante la utilización de un análisis de PCR-RFLP del gen $h r p$, secuenciación de la región $16 \mathrm{~S}$ del ADNr y AFLP's. Más recientemente Fegan \& Prior (2005), plantean la existencia de cuatro grupos genéticos correspondientes a diferentes orígenes geográficos (Asia sensu lato, América, Indonesia y África) y proponen una clasificación jerárquica de este complejo de especies basada en cuatro niveles equivalentes a especie, subespecie, grupos infra-subespecíficos y líneas clonales. Los autores utilizan los términos filotipo y secuevar para definir los grupos subespecíficos e infra-subespecíficos, respectivamente.

Anterior al empleo de metodologías genéticas y moleculares para la caracterización de los miembros del complejo de especies de $R$. solanacearum, era frecuente la utilización de los aspectos patogénicos y de crecimiento en cultivos axénicos de las cepas bacteriales; que para el caso del agente causal del Moko del plátano y banano, comúnmente denominado como raza 2, incluía cuatro categorías: SFR (colonias con forma redonda, pequeña y fluida), B (cepas causantes de marchitamiento rápido en banano), D (cepas causantes de distorción foliar y marchitamiento lento en banano) y $\mathbf{H}$ (aislamientos patogénicos contra plátano pero no contra banano). Uno de los primeros análisis genéticos de los aislamientos de $R$. solanacearum raza 2 fue realizado por Cook et al. (1989) quienes mediante la utilización de RFLP encontraron la existencia de tres genotipos definidos como MLG 24, MLG 25 y MLG 28. Estos grupos se correlacionaban con diferentes orígenes geográficos: MLG24: Centro América, MLG25: Colombia y Perú y MLG28: Venezuela (Fegan 2005). Posteriormente, con el desarrollo de los conceptos de filotipos y secuevares, se determinó que la raza 2 de $R$. solanacearum pertenece al filotipo II y que las cepas de los MLG 24, 25 y 28 correspondían a los secuevares 3,4 y 6 , respectivamente (Fegan 2005). 
A pesar de los avances en la caracterización genética en secuevares de las cepas de la raza 2 de $R$. solanacearum, es necesario continuar evaluando el grado de variabilidad de este patógeno en diferentes ecosistemas, especialmente en ambientes tropicales, donde su efecto patogénico es muy limitante en diversos cultivos agrícolas. Esta situación se evidenció en un estudio realizado con aislamientos de $R$. solanacearum colectados durante un período de 14 años en la isla de Martinica sobre diferentes hospedantes (anturio, cucurbitáceas, tomate y musáceas, entre otras), en el cual sorpresivamente una gran cantidad de cepas correspondieron al filotipo II, secuevar 4, pero no fueron patógenicas a las musáceas evaluadas en el estudio (banano Cavendish AAA y Musa sp. AAB), razón por la cual fueron denominadas como cepas II/4NPB (No pathogenic to banana) (Wicker et al. 2007).

Esta investigación se planteó con el objeto de evaluar el grado de variación genética mediante marcadores moleculares AFLP de una población de aislamientos de $S$. solanacearum procedentes de la región productora de banano de exportación de Urabá (Colombia), como base para el diseño de estrategias de control de la enfermedad del Moko en el cultivo del banano.

\section{MATERIALES Y MÉTODOS}

Aislamientos bacteriales: El estudio incluyó 100 aislamientos procedentes de plantas de banano, suelos y malezas asociadas a cultivos de banano del Urabá Antioqueño y en menor proporción del departamento del Magdalena (Colombia). De estas cepas, 60 habían sido previamente aisladas y purificadas por Obregón (2007) en el Centro de Investigaciones del Banano (Cenibanano), mientras que las cepas Rs074 y Centro Internacional de Agricultura Tropical (CIAT) 1008 fueron suministradas por el CIAT para su utilización como patrones de referencia, al ser representativas del filotipo II de $R$. solanacearum (Cuadro 1). Las cepas empleadas en el estudio fueron colectadas en los municipios de Apartadó,
Carepa, Chigorodó y Turbo del Urabá Antioqueño y su procesamiento inicial fue realizado en el laboratorio de Cenibanano.

Aislamiento y purificación bacterial: Una vez detectadas las plantas de banano con sintomatología de marchitez bacterial, se procedió a aislar la bacteria a partir de pequeñas porciones de tejido vascular, con desinfección previa en etanol por 30s e hipoclorito de sodio al $3 \%$ por $1 \mathrm{~min}$. Este tejido fue macerado y la suspensión resultante cultivada en medio semi-selectivo SMSA modificado (1L: casaminoácidos $1 \mathrm{~g}$, peptona $10 \mathrm{~g}$, glucosa $5 \mathrm{~g}$, cristal violeta $5 \mathrm{mg} / \mathrm{L}$, polimyxin $\beta$-sulfato $100 \mathrm{mg} / \mathrm{L}$, bacitracina $25 \mathrm{mg} / \mathrm{L}$, penicilina $0.5 \mathrm{mg} / \mathrm{L}$, agaragar $17 \mathrm{~g}$, TZC $50 \mathrm{mg} / \mathrm{L}$ ). Para el caso de las muestras de suelo provenientes de los focos de enfermedad, se tomaron $500 \mathrm{~g}$ alrededor de las plantas y a una profundidad de $5 \mathrm{~cm}$. Una vez en el laboratorio se realizaron diluciones seriadas en buffer fosfato $0.05 \mathrm{M}$ a partir de $1 \mathrm{~g}$ de suelo, obteniendo $100 \mu \mathrm{L}$ de las diluciones $10^{-1}$ y $10^{-3}$ para su siembra en medio SMSA modificado.

Las colonias bacteriales con apariencia rojiza, mucoide, borde irregular y halo claro, fueron seleccionadas y transferidas a medio AN (1L: extracto de carne $3 \mathrm{~g}$, peptona $5 \mathrm{~g}$, agar $15 \mathrm{~g}$ ). En todos los aislamientos utilizados en la investigación, incluyendo los colectados y los obtenidos de otras instituciones, se verificó su identidad taxonómica mediante la utilización de los cebadores 759/760 (759: 5' GTC GCC GTC AAC TCA CTT TCC 3'; 760: 5' GTC GCC GTC AGC AAT GCG GAA TCG 3') (Opina et al. 1997). Para esta prueba se tomó una lupada bacterial de cada aislamiento en $100 \mu \mathrm{L}$ de agua destilada estéril y se llevó a ebullición en baño María por 5min, utilizándose $1 \mu \mathrm{L}$ en las reacciones de PCR.

Las amplificaciones de PCR consistieron de un volumen total de $20 \mu \mathrm{L}$ conteniendo $0.1 \mu \mathrm{M}$ de cada cebador, $1 \mathrm{U}$ de Taq ADN polimerasa recombinante (Fermentas, Vilnius, Lithuania), $0.2 \mathrm{mM}$ de cada dNTP, $1 \mathrm{X}$ de buffer de enzima (100mM Tris- $\mathrm{HCl} \mathrm{pH} 8.8 ; 500 \mathrm{mM}$ $\mathrm{KCl}$ y $0.8 \%$ Nonidet $\mathrm{P} 40$ ) y $1.5 \mathrm{mM} \mathrm{MgCl}_{2}$. 


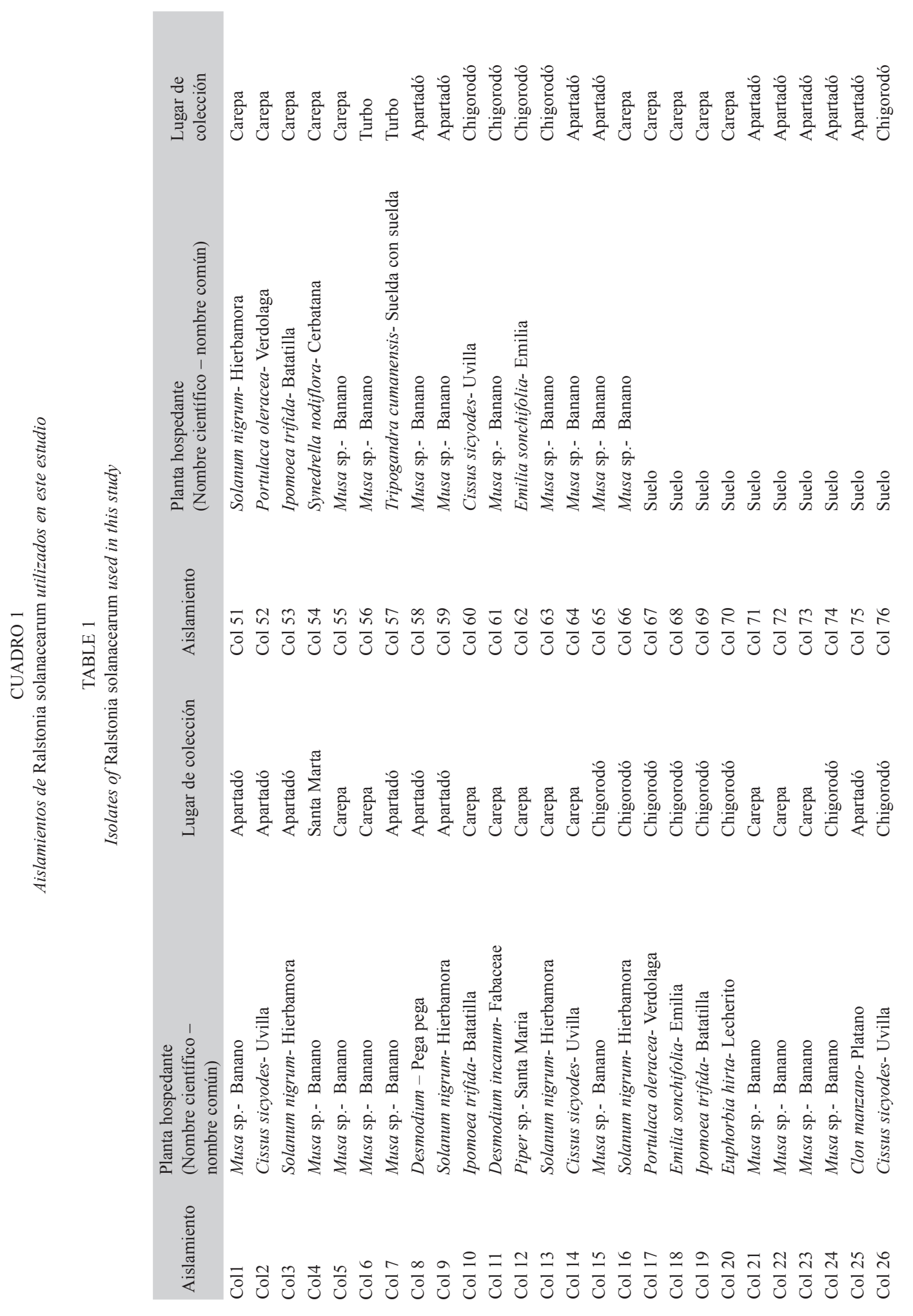




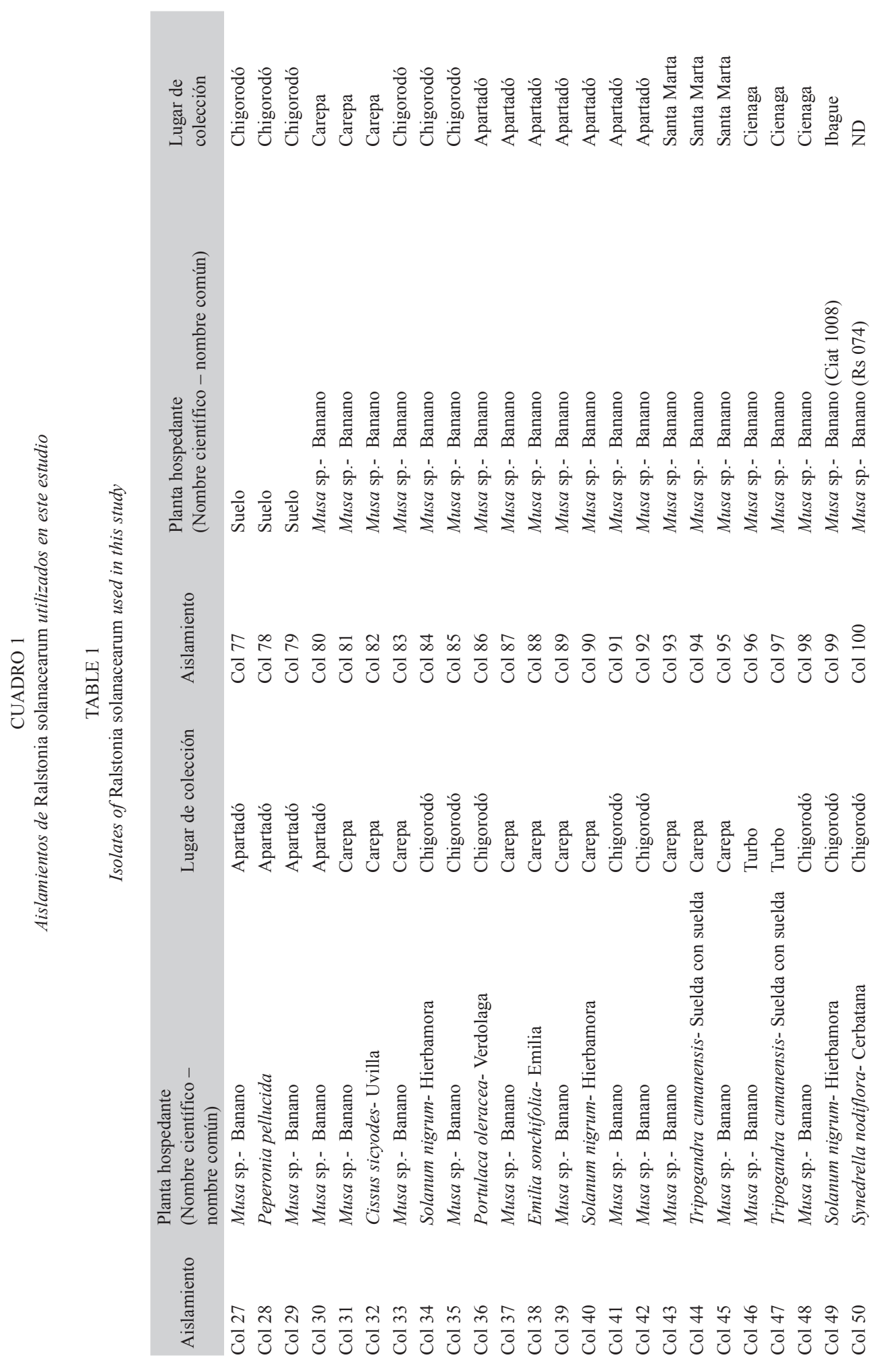


En todas las evaluaciones se incluyó como control positivo las cepas de referencia Rs074 y CIAT1008. Las amplificaciones se realizaron en un termociclador T3 (Biometra, Alemania) y consistieron en una desnaturalización inicial a $96^{\circ} \mathrm{C}$ por $2 \mathrm{~min}$, seguida por 40 ciclos a $94^{\circ} \mathrm{C}$ por $20 \mathrm{~s}, 64^{\circ} \mathrm{C}$ por $20 \mathrm{~s}, 72^{\circ}$ por $30 \mathrm{~s}$ y un período final de extensión a $72^{\circ} \mathrm{C}$ por $5 \mathrm{~min}$. Luego de la amplificación, se tomaron $5 \mu \mathrm{L}$ de los productos de reacción y se separaron por electroforesis en gel de agarosa al 1.5\% en buffer TBE (TBE 5X: $54 \mathrm{~g} / \mathrm{L}$ TrisBase; $27.5 \mathrm{~g} / \mathrm{L}$ de ácido bórico; $20 \mathrm{~mL} / \mathrm{L}$ de EDTA $0.5 \mathrm{M} \mathrm{pH} 8.0$ ), suplementado con $3 \mu \mathrm{L}$ de bromuro de etidio $(10 \mathrm{mg} / \mathrm{mL})$. La visualización de las bandas se realizó bajo luz ultravioleta utilizando el sistema digital de análisis Bio Doc Analyze (Biometra).

Extracción de ADN para AFLP's: Se partió de una lupada bacterial obtenida en medio agar-nutritivo y diluida en $100 \mu \mathrm{L}$ de agua ultrapura estéril para luego centrifugar durante $4 \mathrm{~min}$ a $11000 \mathrm{rpm}$ con el fin de peletizar la bacteria y adicionar $500 \mu \mathrm{L}$ de buffer de extracción $(10 \mathrm{mM} \mathrm{NaCl}, 25 \mathrm{mM}$ EDTA, $10 \mathrm{mM}$ Tris- $\mathrm{HCl} \mathrm{pH} 8.0$ y $100 \mu \mathrm{L}$ de SDS $20 \%$ ), incubándose en baño María a $37^{\circ} \mathrm{C}$ durante $1 \mathrm{~h}$. Posteriormente se agregó 1vol. de fenol - cloroformo y se centrifugó durante $10 \mathrm{~min}$ a 13 000rpm con el fin de separar las fases orgánicas con residuos de proteínas, lípidos y otros componentes celulares. El sobrenadante fue transferido a un nuevo tubo al cual se le adicionó $300 \mu \mathrm{l}$ de cloroformo, centrifugándose nuevamente por $5 \mathrm{~min}$ a $13000 \mathrm{rpm}$. La precipitación de ácidos nucleicos se realizó mediante la adición de $0.6 \mathrm{vol}$. de isopropanol y $0.1 \mathrm{vol}$. de acetato de sodio $3 \mathrm{M}$ pH 5.5 e incubación a $-20^{\circ} \mathrm{C}$ durante al menos $1 \mathrm{~h}$; para finalmente centrifugar a $13000 \mathrm{rpm}$ por $10 \mathrm{~min}$, descartar el sobrenadante y limpiar el pellet con $400 \mu \mathrm{L}$ de Etanol al 70\%. El precipitado se resuspendió en $20 \mu \mathrm{L}$ de agua ultrapura estéril y se procedió a digerir el ARN mediante la adición de $3 \mu \mathrm{L}$ de ARNasa e incubación a $37^{\circ} \mathrm{C}$ durante $12 \mathrm{~h}$. La integridad del ADN se visualizó mediante electroforesis en gel de agarosa al $0.8 \%$ en buffer TBE $1 \mathrm{X}$ suplementado con $3 \mu \mathrm{L}$ de bromuro de etidio $(10 \mathrm{mg} / \mathrm{mL})$. La cantidad de ADN obtenida se determinó por espectrofotometría a $260 \mathrm{~nm}$ de longitud, utilizando un espectrofotómetro Thermo Scientific Genesys $6 \mathrm{Uv}$-Vis (Waltham, MA, USA).

Variabilidad genética de $R$. solanacearum mediante AFLP's: Esta metodología se realizó siguiendo los procedimientos descritos por Vos et al. (1995) y Janssen et al. (1996), con algunas modificaciones propuestas por Poussier et al. (2000) para el estudio de $R$. solanacearum, utilizándose inicialmente cuatro aislamientos de diferente procedencia (Col1, Col11, Col16 y Col26) para la evaluación del grado de polimorfismo generado con las seis combinaciones de cebadores probados. Para esto se realizaron digestiones dobles con las enzimas EcoRI/MseI a partir de $5 \mu \mathrm{L}$ ADN [aprox. 100ng/ $\mu \mathrm{L}$ ], 2X de Buffer Tango Y+, $1.25 \mathrm{U}$ de las enzimas de restricción, $1 \mathrm{mM}$ de DTT y un volumen total de $12.5 \mu \mathrm{L}$. La mezcla fue incubada a $37^{\circ} \mathrm{C}$ durante $2 \mathrm{~h}$ y las reacciones detenidas a $70^{\circ} \mathrm{C}$ por $15 \mathrm{~min}$. La efectividad de la restricción fue monitoreada en un gel de agarosa al $2 \%$, para luego proceder a la ligación de los adaptadores de doble cadena, específicos para cada sitio de restricción generado. Para el caso de MseI: 5' GAC GAT GAG TCC TGA G 3', 5' TAC TCA GGA CTC AT 3' y EcoRI: 5' CTC GTA GAC TGC GTA CC 3', 5' AAT TGG TAC GCA GTC TAC 3'. Las reacciones de ligación consistieron de $25 \mu \mathrm{L}$ de volumen final, incluyendo los $12.5 \mu \mathrm{L}$ de solución de digestión, $1 \mathrm{U}$ de la enzima T4 ADN ligasa, 5 pmoles $/ \mu \mathrm{L}$ de adaptador $E c o$ RI, 50 pmoles $/ \mu \mathrm{L}$ de adaptador MseI, $1 \mathrm{X}$ de buffer de enzima, $0.5 \mathrm{mM}$ de DTT y $0.4 \mathrm{mM}$ de ATP. La mezcla se incubó a $20^{\circ} \mathrm{C}$ por $2 \mathrm{~h}$ y se almacenó a $-20^{\circ} \mathrm{C}$ hasta su utilización. Para la visualización de la digestión-ligación, se tomaron $5 \mu \mathrm{L}$ de la solución y se realizó una electroforesis en gel de agarosa al $1.5 \%$.

Posteriormente, se procedió a realizar las amplificaciones mediante la utilización de los juegos de cebadores +1: EA-MA, EA-MG, EC-MA, EC-MG, EC-MC y EA-MC diseñados a partir de los cebadores EcoR I+0: 
5'-GACTGCGTACCAATT-3' y $M s e \mathrm{I}+0$ : 5'-GATGAGTCCTGAGTA-3'. Las reacciones de PCR consistieron de $5 \mu \mathrm{L}$ de ADN digerido y ligado, $1.25 \mu \mathrm{L}$ de cada cebador [10pmoles/ $\mu \mathrm{L}$ ], $0.8 \mathrm{mM}$ de dNTPs, $2.5 \mathrm{mM}$ de $\mathrm{MgCl}_{2}$, $1 \mathrm{X}$ de buffer de enzima $(100 \mathrm{mM}$ Tris- $\mathrm{HCl} \mathrm{pH}$ $8.8,500 \mathrm{mM} \mathrm{KCl}, 0.8 \%$ Nonidet P40), $2 \mathrm{U}$ de Taq ADN polimerasa recombinante (Fermentas, Vilnius, Lithuania) y un volumen final de $25 \mu \mathrm{L}$. El programa de amplificación fue de 2 min a $94^{\circ} \mathrm{C}$, seguido de 40 ciclos a $94^{\circ} \mathrm{C}$ por $30 \mathrm{~s}, 55^{\circ} \mathrm{C}$ por $1 \mathrm{~min}$ y $72^{\circ} \mathrm{C}$ por $1 \mathrm{~min}$, con una extensión final a $72^{\circ} \mathrm{C}$ por $5 \mathrm{~min}$. Finalmente los productos fueron visualizados en gel de agarosa al $1.5 \%$ y seleccionadas las cuatro combinaciones de cebadores que generaron los perfiles más polimórficos para su utilización con toda la población bajo estudio y su corrido en geles de poliacrilamida al $6 \%+7.5 \mathrm{M}$ de urea.

Para este proceso se utilizó una cámara de electroforesis Biorad (Hercules, CA, USA) con geles de $25 \mathrm{~cm}$. Se realizó un corrido previo a $2000 \mathrm{~V}$ y $55^{\circ} \mathrm{C}$ de temperatura, para luego cargar $5 \mu \mathrm{L}$ de muestra previamente desnaturalizada a $95^{\circ} \mathrm{C}$ por $5 \mathrm{~min}$ y $2 \mu \mathrm{L}$ de buffer de carga (100ml: 0.05g Azul de Bromofenol, $0.05 \mathrm{~g}$ Xilene Cianol, 10ml TBE 10X), y se efectúo un corrido a $2000 \mathrm{~V}$ por $80 \mathrm{~min}$. La visualización de los perfiles se realizó siguiendo una modificación de la metodología de tinción de plata propuesta por Sambrook \& Russell (2001). Para esto se ubicó el gel en una solución fijadora de etanol al $10 \%$ por $8 \mathrm{~min}$, transfiriéndose luego a ácido nítrico al $1 \%$ por 3 min y lavándose con agua desionizada durante 10 s. Posteriormente se adicionó la solución de tinción (1L: $1 \mathrm{~g}$ de nitrato de plata, $1500 \mu \mathrm{L}$ formaldehído) por 30min, lavándose con agua destilada por $1 \mathrm{~min}$, para proceder al revelado $(500 \mathrm{~mL}: 15 \mathrm{~g}$ carbonato de sodio, $750 \mu \mathrm{L}$ formaldehído, $100 \mu \mathrm{L}$ tiosulfato de sodio) por 2-5min. Finalmente se adicionó la solución fijadora (ácido acético glacial al 10\%) por 5 min y se lavó el gel con agua destilada para proceder a la lectura de las bandas.

Análisis de datos: Para cada combinación de cebadores se construyó una matriz binaria basada en la presencia/ausencia de cada banda en los aislamientos evaluados. Para el análisis de agrupamiento de los aislamientos se obtuvo la matriz de distancias con base en el coeficiente de disimilaridad de Jaccard y se realizó el dendrograma utilizando la distancia promedio (UPGMA), validando la estructura del árbol con base en el valor $p$ y la probabilidad de ocurrencia obtenida a través de bootstrap utilizando 10000 remuestreos (repeticiones). Para ello se utilizó el paquete pvclust (Suzuki \& Shimodaira 2006) del programa estadístico R (R Development Core Team, 2008). Posteriormente se establecieron grupos de genotipos con base en el dendrograma, con el fin de realizar un análisis molecular de varianza (AMOVA) propuesto por Excoffier et al. (1992), utilizando el software Arlequin v3.1 (Excoffier et al, 2006). Se realizó una prueba de hipótesis para los componentes de varianza entre y dentro de poblaciones utilizando 1000 permutaciones. Finalmente se calculó el número de loci polimórficos, el índice de diversidad genética de Nei y el índice de diversidad genotípica de Shannon mediante el software POPGENE (Yeh \& Boyle 1997).

\section{RESULTADOS}

Confirmación de la identidad de los aislamientos: En los 100 aislamientos incluidos en el estudio, se confirmó su asociación al complejo de especies $R$. solanacearum, al obtenerse mediante PCR el amplicón esperado de 282pb. Este amplicón fue igualmente obtenido en las cepas de referencia Rs074 y CIAT 1008.

Variabilidad genética de $R$. solanacearum mediante AFLP's: De las seis combinaciones de cebadores evaluadas, se seleccionaron EA-MA, EA-MG, EC-MA, y EC-MC por generar los mayores niveles de polimorfismo entre los aislamientos inicialmente evaluados. Con los cuatro pares de cebadores se registraron a partir de los geles un total de 354 amplicones (EA-MA: 94, EA-MG: 91, EC-MA: 66 y EC-MC: 103 amplicones) que oscilaron entre 80 y 1200 pb. A pesar de haberse empleado la 
metodología con los 100 aislamientos, el análisis final se realizó en las 78 cepas en las que se obtuvo la totalidad de los perfiles electroforéticos con los cuatro marcadores, evitándose sesgos en el estudio por datos perdidos.

La población de $R$. solanacearum resultó altamente variable, con un porcentaje de loci polimórficos del $96.8 \%$, un índice de diversidad genética de Nei de $\mathrm{h}=0.32(\mathrm{SE}=0.16)$ y de diversidad genotípica de Shannon de $\mathrm{I}=0.48$ $(\mathrm{SE}=0.2)$. El dendrograma UPGMA generado dividió los aislamientos en tres grandes grupos (I, II, III), el primero de ellos (grupo I, valor p: 0.79 y bootstrap: 79\%) incluyó 13 aislamientos procedentes de suelos de la región bananera de Urabá. El grado de variación al interior de este grupo fue alto, con un coeficiente de disimilaridad máximo de 0.35. En el segundo grupo (II, valor p:0.96 y bootstrap: $71 \%$ ) se presentaron cinco subgrupos bien definidos, relacionados con un coeficiente de disimilaridad inferior a 0.41 , que con algunas excepciones representan la procedencia de los aislamientos así, IIA: cinco cepas obtenidas en plantas de banano; IIB: siete cepas obtenidas en $S$. nigrum, además de una cepa de Piper sp. y una de Desmodium sp.; IIC: representado por tres cepas de Portulaca oleraceae; IID: subdividido a su vez en cuatro clados, tres de ellos conteniendo aislamientos de banano y plátano y uno con tres cepas de Emilia sonchifolia y una de Euphorbia hirta (IID-4). El subclado IID-1: incluye las cepas identificadas como pertenecientes al secuevar
6 y cuya procedencia es la región bananera de Santa Marta; el subclado IID-2: incluye 20 aislamientos obtenidos en banano de la región de Urabá y el subclado IID-3: contiene siete aislamientos de banano de la región de Urabá, además de un aislamiento de plátano y un aislamiento de Peperonia pellucida. Finalmente, el grupo III (valor p: 0.86 y bootstrap: 29\%) incluye cuatro aislamientos obtenidos de Cissus sicyodes y dos de banano. Este grupo presenta un coeficiente de disimilaridad máximo de 0.41 . Adicional a estos grupos, se presentan algunas cepas que se ubicaron individualmente a lo largo del dendrograma. Algunos ejemplos son la cepa Col16 obtenida de S. nigrum, Col11 de Desmodium incanum y la cepa Col59 de banano. Un aspecto importante del análisis es el hecho que al interior del clado IID, que incluye mayoritariamente cepas de banano se presentan altos niveles de similitud genética y subclados altamente soportados por los análisis de probabilidad y bootstrap (Fig. 1).

El AMOVA demostró que la variación genética total de la población bajo estudio se puede explicar en un $33.9 \%$ debido a diferencias dentro de los grupos, mientras que un $66.10 \%$ se debió a la varianza entre los grupos. El análisis de subestructuración genética resultó significativo ( $\mathrm{Fst}=0.66 ; \mathrm{p}<0.00001$ ), indicando diferenciación genética entre las poblaciones de $R$. solanacearum de la región bananera de Urabá, siendo su hospedante de origen el principal factor asociado a su estructura (Cuadro 2).

\section{CUADRO 2}

Análisis de varianza molecular (AMOVA) basado en análisis con marcadores AFLP en una población de 78 aislamientos de Ralstonia solanacearum de la zona bananera de Urabá (Colombia)

TABLE 2

Analysis of molecular variance (AMOVA) based on AFLP's markers of a population of 78 isolates of Ralstonia solanacearum from the banana-growing region of Urabá (Colombia)

$\begin{array}{lcccc}\text { Fuente de Variación } & \begin{array}{c}\text { Grados de } \\ \text { Libertad }\end{array} & \begin{array}{c}\text { Suma de } \\ \text { Cuadrados }\end{array} & \begin{array}{c}\text { Componentes de } \\ \text { Varianza }\end{array} & \begin{array}{c}\text { Porcentaje de } \\ \text { Variación }\end{array} \\ \text { Entre poblaciones } & 13 & 3170.800 & 41.1190 & 66.10 \\ \text { Dentro de poblaciones } & 67 & 1413.951 & 21.0918 & 33.90\end{array}$

FST: 0.66096. Valor $\mathrm{p}<0.0001$. 


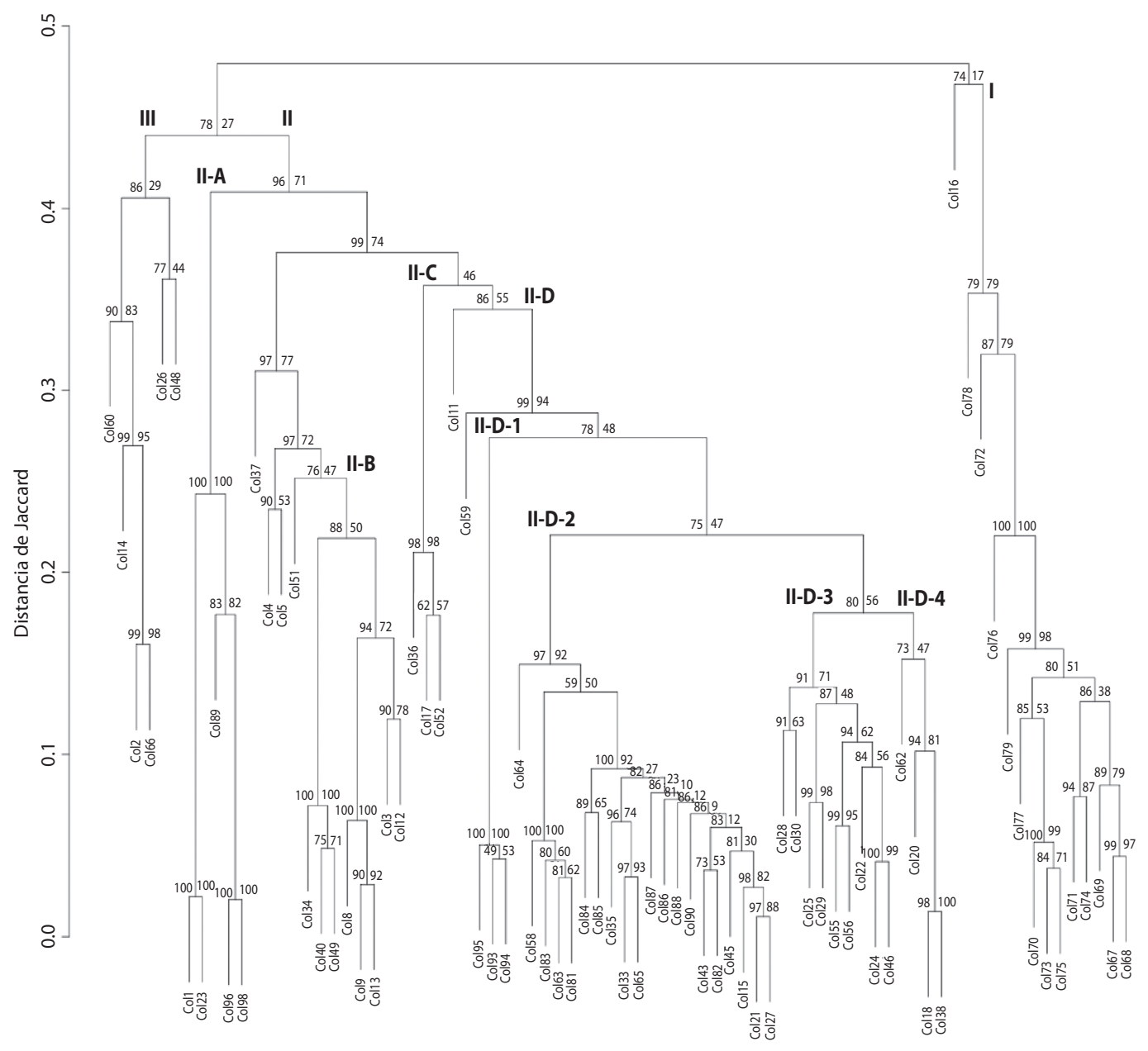

Aislamiento

Fig. 1. Dendrograma UPGMA generado mediante el análisis de marcadores AFLP para una población de 78 aislamientos de Ralstonia solanacearum de la región de Urabá (Colombia). Los números sobre las ramas indican el valor p (a la izquierda) y la probabilidad de bootstrap (a la derecha). Los números romanos indican los grupos principales y secundarios derivados del análisis UPGMA, sus nombres se explican en el texto.

Fig. 1. UPGMA dendrogram generated through analysis of AFLP markers for a population of 78 isolates of Ralstonia solanacearum from the region of Urabá (Colombia). Numbers above branches show p value (left-side) and bootstrap probability (rigth-side). The roman numerals indicate major and secondary groups with the UPGMA analysis, their names are explained in the text.

\section{DISCUSIÓN}

En este estudio se realizó una caracterización molecular del nivel de variabilidad de aislamientos de $R$. solanacearum procedentes de plantaciones de banano, suelos y plantas arvenses de al menos ocho familias botánicas (Asteraceae, Commelinaceae, Convolvulaceae, Euphorbiaceae, Fabaceae, Piperaceae, Portulacaceae y Vitaceae) colectados mayoritariamente en la región de Urabá y algunos en la zona bananera del Departamento del 
Magdalena. Los resultados indican que los 100 aislamientos incluidos en el estudio están asociados al complejo $R$. solanacearum, tal como se desprende de la obtención de un amplicón de $282 \mathrm{pb}$, que también fue generado en las cepas de referencia.

El análisis de diversidad genética utilizando AFLP's reveló la existencia de un alto nivel de variación al interior de la población de $R$. solanacearum evaluada, con niveles de disimilaridad genética entre algunos grupos de cepas que superan valores de 0.47 (ej. cepas obtenidas de suelo vs cepas de Cissus sicyodes). Evaluaciones morfológicas y patogénicas realizadas con cepas colombianas de $R$. solanacearum (Granada et al. 1995, Granada 1996a, 1996b, Martínez \& García 2003, Gómez et al. 2005, Obregón 2007) habían sugerido la existencia de un alto nivel de variación de esta bacteria en Colombia, situación que es confirmada plenamente al menos para la población de $R$. solanacearum asociada a la enfermedad del Moko en la región bananera de Urabá.

Estos niveles de diversidad se ven reflejados por los altos índices de Nei y Shannon encontrados en el análisis poblacional $(\mathrm{h}=0.32$, $\mathrm{I}=0.48$ ) y resultan frecuentes en los diversos estudios que se han realizado con poblaciones de $R$. solanacearum en el mundo y que utilizan marcadores moleculares tipo AFLP's y RAPD's (Poussier et al. 2000, Yu et al. 2003, Grover et al. 2006, Jeong et al. 2007). En estos estudios consistentemente se confirma la división del complejo de especies $R$. solanacearum en cuatro filotipos, sin embargo al interior de cada filotipo se encuentra un alto nivel de variación. Así por ejemplo Yu et al. (2003) al evaluar una población de 55 aislamientos de $R$. solanacerum provenientes de la región cultivadora de jengibre en Hawai mediante 10 marcadores AFLP's, encontraron que los niveles de similitud genética entre aislamientos del mismo cultivo presentaban valores tan bajos como 0.46 a 0.53 , mientras que la disimilaridad genética promedio de la población fue de 0.5. Por otra parte, Grover et al. (2006), al evaluar la diversidad de 44 aislamientos de $R$. solanacearum obtenidos en 16 diferentes terrazas de cultivo de un mismo campo en Shimla (India) detectaron 42 genotipos distintos cuando se estableció como parámetro un índice de similitud de 0.7 , encontrándose además valores de distancia genética entre algunos aislamientos de hasta 0.88 .

El análisis al interior del dendrograma generado en este estudio y el posterior AMOVA, permite la separación de los aislamientos dependiendo de su hospedante de origen (con algunas excepciones), generándose grupos bien definidos para los aislamientos procedentes de suelo de la región de Urabá, así como de las plantas arvenses E. sonchifolia, $S$. nigrum, $P$. oleraceae, $C$. sicyodes.

Los aislamientos obtenidos de banano, se dividieron en al menos cinco subgrupos, uno de los cuales representa el secuevar 6 detectado por Cardozo (2008), mientras que los otros grupos presentan indistintamente cepas del secuevar 4 y cepas asociadas al filotipo II, pero cuyo secuevar no pudo ser definido en dicho estudio, debido a la falta de amplificación en la prueba de PCR múltiple (Cardozo 2008). Un hecho notable de estos grupos de aislamientos obtenidos de banano, es que presentan un menor nivel de variabilidad con respecto a aquellos obtenidos en suelo y algunas plantas arvenses como $C$. sicyodes. Esta situación puede representar la existencia de líneas clonales al interior de los secuevares presentes en la población. Sin embargo, los niveles de variación al interior de cada línea indican que éstas no son estables, pues debido a la ocurrencia de diferentes fuentes de variación como resultado de la presión de selección a que se ven sometidas en los sistemas agrícolas, continuamente se generan nuevos genotipos. Una situación similar fue planteada por Castillo \& Greenberg (2007), quienes determinaron la diversidad genética, el grado de recombinación y la divergencia poblacional de 58 aislamientos representando los diferentes filotipos de la bacteria presentes en diversas regiones del mundo y concluyeron que $R$. solanacearum se presenta como una bacteria fundamentalmente clonal, pero con una alta capacidad de generar nuevos genotipos. El gran potencial de variación que presenta 
$R$. solanacearum fue recientemente confirmado por Grover et al. (2006), quienes luego de evaluar los niveles de variación de una línea clonal de $R$. solanacearum sometida a nueve transferencias en medio de cultivo, determinaron mediante RAPD's la existencia de 22 genotipos diferentes cuando se utilizó como parámetro de separación un nivel de similitud de 0.7. Tal variación, puede explicarse gracias a los altos niveles de transferencia horizontal de genes entre cepas bacteriales de $R$. solanacearum ó con otras especies de procariotes (incluso con archaeabacterias, Gophna et al. 2004) debido a la existencia de múltiples elementos móviles en su genoma (profagos, secuencias de inserción, transposones); a la presencia de sitios calientes (hot spots) de recombinación y a la alta tasa de mutación reportada para esta bacteria (Grover et al. 2006). Un indicativo adicional de la gran variabilidad de este complejo de especies fue aportado por el estudio de Guidot et al. (2007), quienes en el estudio de microarreglos con 5120 genes de la cepa tipo GMI1000 e hibridización con el genoma de 16 cepas representativas de los cuatro filotipos de $R$. solanacearum, determinaron que de la totalidad de genes bajo análisis, tan sólo 2690 (53\%) estaban presentes en todas las 17 cepas evaluadas.

A pesar del hallazgo de una subestructura al interior de la población de $R$. solanacearum de la zona de Urabá con un alto valor de Fst (0.66) y cuyo determinante principal es el hospedante de origen de los aislamientos, la patogenicidad en banano de las cepas procedentes de plantas arvenses utilizadas en este estudio fue probada en un trabajo reciente realizado por Obregón (2007), quien luego de inocular plantas del clon Gran enano de dos meses de edad y propagadas por cultivo in vitro, encontró que 34 de las cepas (obtenidas de Cissus sicyodes, Solanum nigrum, Emilia sonchifolia, Ipomoea trifida, Portulaca oleraceae, Piper sp., Euphorbia hirta, Synedrella nodiflora, Desmodium sp., Peperonia pellucida y Tripogandra cumanenses) tenían la capacidad de inducir los síntomas de marchitez y necrosis vascular que caracterizan la enfermedad del Moko de las musáceas. Esto posiblemente indica que aunque en general, se presentan diferencias genéticas entre aislamientos de $R$. solanaceraum procedentes de plantas arvenses y/o suelos con respecto a aquellos colectados en plantas de banano, aquellos genes como hrp (respuesta hipersensible y patogenicidad), eg (endoglucanasa) y flic $\mathrm{C}$ (flagelina) ubicados en el megaplásmido bacterial asociados a patogenicidad (Salanoubat et al. 2002) son constantemente transferidos horizontalmente entre las cepas que comparten los agroecosistemas bananeros, de manera que su rango de hospedantes se extiende, posibilitándose así la afección de otras plantas, en este caso Musa sp. Sin embargo, de gran interés resulta la presencia de aislamientos originalmente obtenidos de plantas de banano compartiendo clados con aislamientos de plantas arvenses (ej. Clado III), pues esto refleja que no sólo los genes del megaplásmido son similares, sino también que las regiones de su cromosoma bacterial comparten altos niveles de identidad. Es por esto que de gran interés resultaría la secuenciación masiva de ambos replicones en aislamientos seleccionados con base en el análisis de AFLP aquí realizado, con el fin de profundizar en la búsqueda de respuestas al por qué a pesar de presentarse estructuración al interior de la población estudiada, los miembros de diferentes clados no presentan patogenicidad diferencial.

Desde el punto de vista práctico, los hallazgos de esta investigación y la realizada por Obregón (2007), reafirman la necesidad de eliminar completamente las plantas arvenses de los focos detectados con la enfermedad de Moko en la región de Urabá, evitar al máximo el transporte de suelos infectados con la bacteria y garantizar la correcta desinfectación de las herramientas de trabajo utilizadas en las prácticas culturales, por cuanto la población de $R$. solanacearum en esta zona presenta un alto potencial de ser patogénica a plantas de banano. Estos resultados representan una grave problemática epidemiológica para el manejo de esta enfermedad en las regiones bananeras de Colombia y sugieren la necesidad de incluir en evaluaciones de resistencia de variedades, control químico y capacidad de sobrevivencia 
de la bacteria en los focos tratados, de un alto número de genotipos, los que deberían ser seleccionados con base en su hospedante de origen.

\section{AGRADECIMIENTOS}

Esta investigación se financió con el apoyo de COLCIENCIAS (Contrato 8242-0716025), AUGURA y la Universidad Nacional de Colombia. Los autores agradecen a Mónica Obregón de Cenibanano y Elizabeth Álvarez del CIAT, por proveer algunas de las cepas utilizadas en el estudio.

\section{RESUMEN}

La enfermedad del moko de las musáceas, causada por la bacteria Ralstonia solanacearum, es uno de los problemas fitopatológicos más importantes de la agroindustria del banano en los países tropicales. En Urabá y el Magdalena (Colombia), las principales regiones exportadoras de banano en Colombia, esta enfermedad provoca una destrucción estimada en $16.5 \mathrm{ha} /$ año. La bacteria presenta un nivel extremadamente alto de variación genética que afecta las medidas de control. Este es el primer estudio de su variación en Colombia y se hizo con los marcadores moleculares AFLP en una población de 100 aislamientos de plantas de banano, suelos y arvenses. El alto nivel de diversidad genética, con índices de Nei y de Shannon de $\mathrm{h}=0,32$ y $\mathrm{I}=0,48$, respectivamente, y la AMOVA, demostró que esta población es subestructurada $(\mathrm{Fst}=0,66)$ : el hospedero es el principal factor de diferenciación. Aun así, las pruebas anteriores mostraron que todas las variedades presentan patogenicidad en Musa.

Palabras clave: AFLP, enfermedad del Moko, marcadores moleculares, Musa sp. Ralstonia solanacearum

\section{REFERENCIAS}

Cardozo, C. 2008. Diversidad genética de Ralstonia solanacearum en la zona bananera de Urabá. Tesis Maestría Biotecnología, Universidad Nacional de Colombia, Medellín.

Castañeda, D.Y \& J.A. Espinosa 2005. Comportamiento e impacto de la enfermedad del Moko en la zona de Urabá (Colombia), en las últimas tres décadas y media y propuesta de un índice de riesgo de la enfermedad. Rev. Fac. Nal. Agr. Medellín 58: 2587-2599.
Castillo, J.A. \& J.T. Greenberg. 2007. Evolutionary dinamics of Ralstonia solanacearum. Appl. Environ. Microbiol. 73: 1225-1238.

Cook, D., E. Barlow \& L. Sequeira. 1989. Genetic diversity of Pseudomonas solanacearum: detection of restriction fragment polymorphism with DNA probes that specify virulence and hypersensitive response. Mol. Plant - Microbe Interact. 2: 113-121.

Excoffier, L., P.E. Smouse \& J.M. Quattro. 1992. Analysis of molecular variance inferred from metric distances among DNA haplotypes: application to human mitocondrial DNA restriction sites. Genetics 131: 479-491.

Excoffier, L., L. Guillaume \& S. Schneider. 2006. Arlequin ver. 3.1: An integrated software package for populations genetics. Computational and molecular population genetics lab (CMPG), Universidad de Berna, Berna, Suiza.

Fegan, M., M. Taghavi, L. Sly \& A.C. Hayward. 1998. Phylogeny, diversity and molecular diagnostics of Ralstonia solanacearum, p. 19-33. In C. Allen, P. Prior \& A.C. Hayward (eds.). Bacterial wilt: the disease and the Ralstonia solanacearum species complex. American Phytopathological Society, San Pablo, EEUU.

Fegan, M. 2005. Bacterial wilt diseases of banana: evolution and ecology, p. 379-386. In C. Allen, P. Prior \& A.C. Hayward (eds.). Bacterial wilt: the disease and the Ralstonia solanacearum species complex. American Phytopathological Society, San Pablo, EEUU.

Fegan, M. \& P. Prior. 2005. How complex is the "Ralstonia solanacearum species complex"? p. 449-461. In C. Allen, P. Prior \& A.C. Hayward (eds.). Bacterial wilt: the disease and the Ralstonia solanacearum species complex. American Phytopathological Society, San Pablo, EEUU.

Fegan, M. \& P. Prior. 2006. Diverse members of the Ralstonia solanacearum species complex cause bacterial wilts of banana. Australas. Plant Pathol. 35: 93-101.

Gillings, M.R. \& Y.P. Fahy. 1994. Genomic fingerprinting: towards a unified view of the Pseudomonas solanacearum species complex, p. 95-112. In A.C. Hayward \& G.L. Hartman (eds.). Bacterial wilt: the disease and its causative agent, Pseudomonas solanacearum. CABI, Wallingford, Reino Unido.

Gómez, E.A., E. Alvárez \& G. Llano. 2005. Identificación y caracterización de cepas de Ralstonia solanacearum raza 2, agente causante del Moko de plátano en Colombia. Fitopatol. Colomb. 28: 71-75. 
Granada, G., M. Howell, \& D. Cook. 1995. Caracterización molecular de cepas colombianas de Pseudomonas solanacearum raza 2 , a través de la técnica de polimorfismo de longitud de fragmentos de restricción, $\mathrm{p}$. 187-191. In Instituto Colombiano Agropecuario, ICA (ed.). Mejoramiento de la producción del cultivo del plátano. Corpoica, Armenia, Colombia.

Gophna, U., R.L. Charlebois \& W.F. Doolittle. 2004. Have archaeal genes contributed to bacterial virulence? Trends. Microbiol. 12: 213-219.

Granada, G.A. 1996a. Hospederos de Pseudomonas solanacearum raza 2, bajo condiciones de la zona platanera del departamento del Quindío, p. 95- 96. In Comité departamental de cafeteros del Quindío (ed.). Tecnología del eje cafetero para la siembra y explotación rentable del cultivo del plátano. Tercer informe técnico, 1994-1996. Corpoica, Armenia, Colombia.

Granada, G.A. 1996b. Supervivencia de Pseudomonas solanacearum raza 2, bajo condiciones de la zona platanera del departamento del Quindío, p. 96. In Comité departamental de cafeteros del Quindío (ed.). Tecnología del eje cafetero para la siembra y explotación rentable del cultivo del plátano. Tercer informe técnico, 1994-1996. Corpoica, Armenia, Colombia.

Grover A., W. Azmi, A.V. Gadewar, D. Pattanayak, P.S. Naik, G.S. Shekhawat \& S.K. Chakrabarti. 2006. Genotypic diversity in a localized population of Ralstonia solanacearum as revealed by random amplified polymorphic DNA markers. J. Appl. Microbiol. 101: 798-806.

Guidot, A., P. Prior, J. Schoenfeld, S. Carrère, S. Genin \& C. Boucher. 2007. Genomic structure and phylogeny of the plant pathogen Ralstonia solanacearum inferred from gene distribution analysis. J. Bacteriol. 189: $377-387$.

Hayward, A.C. 1995. Research on bacterial wilt: a perspective on international linkages and access to the literature, p. 1-8. In C. Allen, P. Prior \& A.C. Hayward (eds.). Bacterial wilt: the disease and the Ralstonia solanacearum species complex. American Phytopathological Society, San Pablo, EEUU.

Janssen, P., R. Coopman, G. Huys, J. Swings, M. Bleeker, P. Vos, M. Zabeau \& K. Kersters. 1996. Evaluation of the DNA fingerprinting method AFLP as a new tool in bacterial taxonomy. Microbiology 142: 18811893.

Jeong, Y., J. Kim \& Y. Kang. 2007. Genetic diversity and distribution of Korean isolates of Ralstonia solanacearum. Plant Dis. 91: 1277-1287.
Obregon, M. 2007. Diagnóstico, hospederos y sobrevivencia de la bacteria Ralstonia solanacearum en banano y aplicaciones al control integrado de la enfermedad en la zona de Uraba. Tesis Maestría Ciencias Agrarias, Universidad Nacional de Colombia, Medellín.

Opina , N., F. Tavner, G. Holloway, J.F. Wang, T. Li, R. Maghirang, M. Fegan, A.C. Hayward, V. Krishnapillai, W.F. Hong, B.W. Holloway \& J.N. Timmis. 1997. A novel method for development of species and strain - specific DNA probes and PCR primers for identifying Burkholderia solanacearum (formely Pseudomonas solanacearum). Asian - Pac. J. Mol. Biol. Biotechnol. 5: 19-33.

Poussier, S., D. Trigalet-Demery, P. Vandewalle, B. Goffinet, J. Luisetti \& A. Trigalet. 2000. Genetic diversity of Ralstonia solanacearum as assessed by PCR-RFLP of the hrp gene region, AFLP and 16S rRNA sequence analysis, and identification of an African subdivision. Microbiology 146: 1679-1692.

R Development Core Team. 2008. R: A Language and Environment for Statistical Computing. R Foundation for Statistical Computing, Vienna, Austria.

Salanoubat, M., S. Genin \& F. Artiguenave. 2002. Genome sequence of the plant pathogen Ralstonia solanacearum. Nature 415: 497-502.

Sambrook, J. \& D.W. Russell. 2001. Molecular Cloning: A Laboratory Manual. Cold Spring Harbor Laboratory, Nueva York, EEUU.

Suzuki, R. \& H. Shimodaira. 2006. Pvclust: an R package for assessing the uncertainty in hierarchical clustering. Bioinformatics 22: 1540-1542.

Taghavi, M., C. Hayward, L. Sly \& M. Fegan, 1996. Analysis of the phylogenetic relationships of strains of Burkholderia solanacearum, Pseudomonas syzygii, and the blood disease bacterium of banana based on 16S rRNA gene sequences. Inter. J. Syst. Bacteriol. 46: $10-15$.

Vos, P., R. Hogers, M. Bleeker, M. Reijans, T. Van De Lee, M. Hornes, A. Frijters, J. Pot, J. Peleman, M. Kuiper, M. \& M. Zabeau. 1995. AFLP a new technique for DNA fingerprinting. Nucleic Acids Res. 23: $4407-$ 4414.

Wicker, E., L. Grassart, R. Coranson-Beaudu, D. Mian, C. Guilbaud, M. Fegan \& P. Prior. 2007. Ralstonia solanacearum strains for Martinique (French West Indies) exhibiting a new pathogenic potential. Appl. Environ. Microbiol. 73: 6790-6801. 
Yabuuchi, E., Y. Kosako, I. Yano, H. Hotta, \& Y. Hishiuchi. 1995. Transfer of two Burkholderia and Alcaligenes species to Ralstonia Gen. Nov.: proposal of Ralstonia pickettii (Ralston, Palleroni and Doudoroff 1973) Comb. Nov., Ralstonia solanacearum (Smith 1986) Comb. Nov. and Ralstonia eutrofha (Davis 1969) Comb. Nov. Microbiol. Immunol. 39: 897-904.

Yeh, F.C. \& T.J.B. Boyle. 1997. Population genetic analysis of co-dominant and dominant markers and quantitative traits. Belg. J. Bot. 129: 157.

Yu, Q., A.M. Alvarez, P.H. Moore, F. Zee, M.S. Kim, A. De Silva, P.R. Hepperly \& R. Ming. 2003. Molecular
Diversity of Ralstonia solanacearum isolated from Ginger in Hawaii. Phytopathology 93: 1124-1130.

\section{REFERENCIAS DE INTERNET}

Martínez, A. \& F. García. 2003. Manejo de la enfermedad del Moko ó ereke en el cultivo del plátano para la Orinoquía colombiana. Corpoica ecoregión Caribe (Consultado 10 Diciembre 2007, www.turipana.org/ anejo_enfermedad_moko.htm.).

Ministerio de Agricultura y Desarrollo Rural-MADR. 2006. Perfil del cluster del banano. Colombia (Consultado 12 Agosto 2007, www.minagricultura.gov.co). 